\begin{tabular}{|l|l|l||}
\hline \multicolumn{2}{|c|}{ PublisherInfo } \\
\hline \hline PublisherName & $:$ & BioMed Central \\
\hline \hline PublisherLocation & $:$ & London \\
\hline \hline PublisherImprintName & $:$ & BioMed Central \\
\hline \hline
\end{tabular}

\title{
Early CAVH improves haemodynamics in sepsis
}

\begin{tabular}{|l|l|l||}
\hline \multicolumn{2}{|c||}{ ArticleInfo } \\
\hline \hline ArticleID & $:$ & 4097 \\
\hline \hline ArticleDOI & $:$ & $10.1186 /$ ccf-1999-1563 \\
\hline \hline ArticleCitationID & $:$ & 1563 \\
\hline \hline ArticleSequenceNumber & $:$ & 34 \\
\hline \hline ArticleCategory & $:$ & Paper Report \\
\hline \hline ArticleFirstPage & $:$ & 1 \\
\hline \hline ArticleLastPage & $:$ & 5 \\
\hline \hline & & RegistrationDate : 1999-8-27 \\
\hline ArticleHistory & $:$ & OnlineDate \\
\hline \hline ArticleCopyright & $:$ & Current Science Ltd1999-8-27 \\
\hline \hline ArticleGrants & $:$ & \\
\hline \hline ArticleContext & $:$ & 130541111 \\
\hline \hline
\end{tabular}




\section{Keywords}

Cardiac depression, dogs, haemofiltration, myocardial depressant factor, sepsis

\section{Comments}

The authors can be congratulated on the detail of their design with multiple control groups in an attempt to exclude co-factors so that their hypothesis could be confidently confirmed. One of the many criticisms when trying to extrapolate the results of haemofiltration in animal models of sepsis to clinical medicine is that the timing of introduction of haemofiltration is usually much later in the human population, and the authors have convincingly demonstrated that this is important and proposed a mechanism as well (reduction in FCS activity). However haemodynamic deterioration is still often worse before haemofiltration is introduced in the clinical setting when compared to this animal study, which may well explain why human studies on the same theme have been so disappointing. Other criticisms when extrapolating to clinical medicine also remain with this study - the mechanism used to induce sepsis in the animal model probably shows different cytokine patterns to the clinical scenario, sepsis is hypodynamic in this model when compared to the clinical hyperdynamic findings, and no antibiotics were given.

\section{Introduction}

Removal of circulating inflammatory mediators by haemofiltration may have beneficial haemodynamic effects in sepsis. However, there has been varying results in different animal models of sepsis, and failure to show an improvement in haemodynamics may be because of the model used or because haemofiltration was introduced too late during the course of sepsis. This study utilises a canine model of Pseudomonas aeruginosa pneumonia which has a predictable time course of haemodynamic demise, with a minor drop in mean arterial pressure (MAP) at $2 \mathrm{~h}$ and a significant drop (to 2/3 of baseline) at $5 \mathrm{~h}$. Consequently, introduction of haemofiltration at these two time points may result in differing haemodynamic effects.

Myocardial depression by a circulating mediator of sepsis may be involved in the haemodynamic changes in sepsis. Filterable cardiopressant substance (FCS), measured by a right ventricular trabecular bioassay, is a circulating mediator $(10,000-30,000 \mathrm{Da})$ which has previously been implicated in myocardial depression during sepsis. Removal of this substance by haemofiltration reverses this effect. 


\section{Aims}

To investigate the changes in haemodynamics between early haemofiltration (commenced at $2 \mathrm{~h}$ in the above described model), and late haemofiltration (commenced at $5 \mathrm{~h}$ ) when major haemodynamic effects have already occurred. FCS activity was also measured over time to determine whether removal of FCS by haemofiltration corresponded to improvements in haemodynamics.

\section{Methods}

The conduct of anaesthesia, measurement of haemodynamics, FCS activity and innoculation of Pseudomonas into the dogs' lungs is described well in the text. Haemodynamic variables were then followed in various groups:

\section{Early haemofiltration (commenced at $2 \mathrm{~h}$ post-inoculation)}

-Instillation of Pseudomonas broth into canine lungs

I. Early haemofiltration $(n=12)$

II. No haemofiltration $(n=13)$

-Instillation of sterile broth into canine lungs (sham group)

III. Early haemofiltration $(n=4)$

IV. No haemofiltration $(n=5)$

\section{Late haemofiltration (commenced at $5 \mathrm{~h}$ post-innoculation)}

- Instillation of Pseudomonas broth into canine lungs

V. Late haemofiltration $(n=13)$

VI. No haemofiltration $(n=13)$

- Instillation of sterile broth into canine lungs (sham group)

VII. Late haemofiltration $(n=4)$

VIII. No haemofiltration $(n=4)$ 
Finally, to ensure that any beneficial effects were not just due to an unknown factor as a consequence of blood passing round the haemofiltration circuit, five animals were innoculated with Pseudomonas and after $2 \mathrm{~h}$ blood was passed through the haemofilter circuit but not filtered.

An important factor in the methology was that haemofiltration was performed at flow rates of 2-3 1/ min which greatly exceeds those in the clinical situation.

\section{Results}

In the early haemofiltration group, MAP, stroke work (SW) and cardiac output (CO) were well maintained in the pneumonia group with haemofiltration (Group I), whereas values significantly decreased in the pneumonia group without haemofiltration (Group II). There were no changes in the sham pneumonia groups (Groups III \& IV). Conversely in the late haemofiltration group no improvements in haemodynamics were shown in the pneumonia group with haemofiltration (Group V) when compared to the pneumonia group without haemofiltration (Group VI). As expected there were no changes in the sham pneumonia groups (Groups VII \& VIII).

In contrast to Group I, the early pneumonia group receiving sham haemofiltration showed a significant decline in haemodynamics.

Finally, FCS activity increased in both Groups I and II at $2 \mathrm{~h}$ post-inoculation, and continued to rise at $5 \mathrm{~h}$ in Group II but showed a significant reduction in activity at $5 \mathrm{~h}$ after haemofiltration (Group I). FCS activity remained high in the late haemofiltration group (Group V) compared to Group I after haemofiltration, although was significantly less than Group VI showing that haemofiltration was filtering some FCS activity even at this late stage. The sham pneumonia groups (Groups III, IV, VII, VIII) showed no changes in FCS activity, and the sham haemofiltration group had no effect on the increase in FCS activity.

\section{Discussion}

Early haemofiltration in this canine model of pneumonia improves haemodynamics, and this may be partly explained by filtration of a cardiac depressant factor (FCS). Although late haemofiltration does reduce FCS activity, its lack of effect in improving haemodynamic variables may be explained by lack of reversibility of FCS to the myocardial cell. Alternatively, FCS activity may be significantly greater at this time period, which isn't detected by the particular assay used by the authors. The authors comment that the very high flow rates used in this animal model may make extrapolation into clinical medicine difficult. 


\section{References}

1. Mink SN, Li X, Bose D, Gu M, Liu G, Jacobs H, Light RB: Early but not delayed continuous arteriovenous haemofiltration improves cardiovascular function in sepsis in dogs. Intensive Care Med. 1999, 25: 733-743.

This PDF file was created after publication. 